\title{
Impact and clinical profiles of Mycoplasma pneumoniae co-detection in childhood community-acquired pneumonia
}

\author{
Meng-chuan Zhao', Le Wang ${ }^{1}$, Fang-zhou Qiu², Li Zhao ${ }^{2}$, Wei-wei Guo ${ }^{1}$, Shuo Yang ${ }^{1}$, Zhi-shan Feng ${ }^{3 *}$ and \\ Gui-xia Li ${ }^{1 *}$
}

\begin{abstract}
Background: Increasing number of hospitalized children with community acquired pneumonia (CAP) is cOdetected with Mycoplasma pneumoniae (Mp). The clinical characteristics and impact of Mp co-detected with other bacterial and/or viral pathogens remain poorly understood. The purpose of this study was to evaluate the demographic and clinical features of CAP children with Mp mono-detection and Mp co-detection.

Methods: A total of 4148 hospitalized children with CAP were recruited from January to December 2017 at the Children's Hospital of Hebei Province, affiliated to Hebei Medical University. A variety of respiratory viruses, bacteria and $M p$ were detected using multiple modalities. The demographic and clinical features of CAP children with $\mathrm{Mp}$ mono-detection and Mp co-detection were recorded and analyzed.

Results: Among the 110 CAP children with Mp positive, 42 (38.18\%) of them were co-detected with at least one other pathogen. Co-detection was more common among children aged $\leq 3$ years. No significant differences were found in most clinical symptoms, complications, underlying conditions and disease severity parameters among various etiological groups, with the following exceptions. First, prolonged duration of fever, lack of appetite and runny nose were more prevalent among CAP children with Mp-virus co-detection. Second, Mp-virus (excluding HRV co-detected patients were more likely to present with prolonged duration of fever. Third, patients co-detected with Mp-bacteria were more likely to have abnormal blood gases. Additionally, CAP children with Mp-HRV co-detection were significantly more likely to report severe runny nose compared to those with Mp mono-detection.

Conclusion: $M p$ co-detection with viral and/or bacterial pathogens is common in clinical practice. However, there are no apparent differences between $\mathrm{Mp}$ mono-detection and $\mathrm{Mp}$ co-detections in terms of clinical features and disease severity.
\end{abstract}

Keywords: Co-detection, Mycoplasma pneumoniae, Outcomes, Community-acquired pneumonia, Children

\section{Background}

Community-acquired pneumonia (CAP) is a leading cause of hospitalization among infants and children worldwide, especially in developing countries. A variety of respiratory viruses such as Influenza A (Flu A), respiratory syncytial

\footnotetext{
*Correspondence: 1173791762@qq.com; 13832179762@139.com ${ }^{3}$ Department of Laboratory Medicine, People's Hospital of Hebei Province, 384 Heping West Road, Shijiazhuang 050051, Hebei Province, China ${ }^{1}$ Institute of Pediatric Research, Children's Hospital of Hebei Province, affiliated to Hebei Medical University, 133 Jianhua South Street, Shijiazhuang 050031, Hebei Province, China

Full list of author information is available at the end of the article
}

virus (RSV), adenovirus (ADV) and human metapneumovirus (HMPV), and bacteria such as Streptococcus pneumoniae, Hemophilus influenza, Staphylococcus aureus and Mycoplasma pneumoniae $(\mathrm{Mp})$ are associated with childhood CAP [1-4]. Notably, $M p$ accounts for $10-40 \%$ of CAP in children, and as high as $18 \%$ of cases with CAP require hospitalization [4-6]. In recent years, with the development more frequent use of molecular diagnostics, an increasing number of hospitalized CAP children are diagnosed with mixed viral-bacterial detections, and $\mathrm{Mp}$ codetection is not uncommon [7-10]. However, the clinical

(C) The Author(s). 2019 Open Access This article is distributed under the terms of the Creative Commons Attribution 4.0 International License (http://creativecommons.org/licenses/by/4.0/), which permits unrestricted use, distribution, and 
characteristics and implications of $M p$ co-detection are poorly described.

To better characterize the impacts of $M p$ co-detection on CAP children, a 12-month prospective study was carried out to examine the demographic and clinical characteristics of CAP caused by $M p$, including monodetection and co-detection. In addition, this study assessed the differences in demographic and clinical features between mono- and co-detected CAP children.

\section{Methods}

\section{Study population and case definitions}

This prospective study was conducted on children $(<18$ years) with CAP admitted at the Children's Hospital of Hebei Province, affiliated to Hebei Medical University, China, over a period of 12 months (from January 1, 2017 to December 31, 2017). The diagnostic criteria for CAP included: (a) clinical manifestations: fever, cough and/or dyspnea; (b) auscultatory findings: abnormal breath sounds, wheezes or crackles; and (c) radiographic evidence: consolidation, other infiltrate or pleural effusion.

CAP patients with positive results of $M p-D N A$ bronchoalveolar lavage fluid (BALF) or $\mathrm{a} \geq 4$-fold rise in IgG titer were considered to have $M p$ positive. If only $M p$ was detected, the patients were considered to have $M p$ mono-detection. Co-detection was defined as detection of $M p$ with $\geq 1$ other bacterial or viral pathogen. Children with co-detection were stratified into two groups: $M p$-virus co-detection and $M p$-bacteria co-detection. The $M p$-virus co-detection group was further stratified into two subgroups: $M p-H R V$ co-detection and $M p$-virus (excluding $H R V$ ) co-detection.

\section{Data collection}

The demographic, clinical, laboratory and other related data of $\mathrm{Mp}$-positive children were collected: (1) demographic characteristics: gender and age; (2) clinical information: duration of fever, cough, wheezing and gastrointestinal symptoms (diarrhea or vomiting); (3) laboratory results: peripheral leukocyte, neutrophil and lymphocyte counts, C-reactive protein (CRP) levels and chest radiographic findings; and (4) disease severity parameters: incidence of severe CAP [11], length of hospitalization, requirement for mechanical ventilation and admission to the PICU.

\section{Specimen collection and laboratory testing}

Blood, serum, nasopharyngeal aspirates (NPAs) and BALF specimens were obtained for pathogen detection using multiple modalities.

Real-time polymerase chain reaction (PCR) was performed for $M p-D N A$ detection in BALF specimens using a quantitative diagnostic kit (DaAn Gene Co. Ltd., Guangzhou, China) [12]. Serum IgG against $M p$ was evaluated by a commercial test kit (Virion-Serion, Germany) according to the manufacturer's instructions. Criteria for the diagnostic test were defined as IgG $\geq 4$-fold titers [13].

The NPAs collected from all patients were tested simultaneously for Flu A, Influenza B (Flu B), Influenza $A$ H1N1 pdm09 (09H1), influenza H3N2 (H3), human parainfluenza virus (HPIV), RSV, rhinovirus (HRV), $A D V$, HMPV, human bocavirus (HBoV), human coronavirus (HCoV), Chlamydia (Ch) and $\mathrm{Mp}$ using a GeXPbased multiplex reverse transcription PCR assay [14]. The presence of bacteria and fungi was determined on admission by a positive result in blood specimen and/or BALF culture with the use of standard techniques.

\section{Statistical analysis}

Statistical analyses were performed using SPSS 13.0.1 statistics package (SPSS Inc., Chicago, USA). In brief, the demographic and clinical manifestations of all children with $M p$ positive were presented as absolute frequencies or rates for categorical variables, median (interquartile range) values for quantitative variables. Multiple sets of independent continuous data were compared using the Kruskale-Wallis test, while two sets of independent continuous data were compared by the Mann-Whitney U test. Categorical variables were analyzed using the Pearson Chi-square or Fisher's Exact Test. The level of statistical significance was set at $P<$ 0.05 .

\section{Results}

\section{Study population and microbiological diagnosis}

Between January 1, 2017 and December 31, 2017, 4148 patients who met the criteria of CAP were enrolled. Among them, 110 (2.65\%) were defined as $M p$ positive (Table 1). Of these 110 patients, $68(61.82 \%)$ were detected with only $M p, 42(38.18 \%)$ were detected with at least one other pathogen, $30(27.27 \%)$ were detected with one or more viruses, 7 (6.36\%) were detected with one or more bacteria, and the remaining 5 (4.55\%) were detected with both bacterial and viral pathogens (Table 2).

\section{Demographic characteristics}

Among the 110 patients with $M p$ positive, the median age was 5 years, which was significantly higher compared to that of 4148 CAP children (median age: 0.5 years, $P<$ 0.001 ). Approximately $57.3 \%$ were male, and the gender distribution did not differ significantly between children with $M p$ positive and CAP $(P=0.094)$. Co-detection was more prevalent in children aged $\leq 3$ year compared to those aged $>3$ years old $(64.29 \%$ vs. $29.27 \% ; P=0.001)$. The median age of CAP children with $M p$-virus codetection $(P=0.009), M p-H R V$ co-detection $(P=0.004)$ 
Table 1 The results of Mp detection for 4148 patients with CAP

\begin{tabular}{|c|c|c|c|c|}
\hline Results & Mp -DNA (BALF) & $M p-D N A(N P A)^{a}$ & $\operatorname{lgG}$ (paired sera) & NO. \\
\hline \multirow[t]{3}{*}{$M p$ positive $(N=110)$} & + & + & I & 98 \\
\hline & + & + & + & 6 \\
\hline & + & + & / & 6 \\
\hline \multirow[t]{4}{*}{ Mp negative $(N=4038)$} & - & + & / & 4 \\
\hline & / & + & / & 62 \\
\hline & / & - & / & 3941 \\
\hline & / & - & - & 31 \\
\hline
\end{tabular}

Mp Mycoplasma pneumoniae, CAP community-acquired pneumonia, BALF bronchoalveolar lavage fluid, NPAs nasopharyngeal aspirates

The NPAs were tested simultaneously for Mp, Chlamydia and 11 common respiratory viruses using a GeXP-based multiplex reverse transcription PCR assay, thus Mp-DNA (NPAs) was tested for all patients

and $M p$-virus (excluding $H R V)$ co-detection $(P=0.045)$ was significantly younger compared to those with $M p$ mono-detection (Table 3). Gender distribution did not differ significantly among various etiological groups

Table 2 Etiologic agents of 110 children with Mp positive

\begin{tabular}{|c|c|}
\hline Etiologic agents & Proportion (\%) \\
\hline Mp mono-detection & $68(61.82)$ \\
\hline Mp co-detection & 42(38.18) \\
\hline Virus & $30(27.27)$ \\
\hline$M p+H R V$ & 20 \\
\hline$M p+H P I V$ & 6 \\
\hline$M p+H R V+H P I V$ & 1 \\
\hline$M p+A D V$ & 1 \\
\hline $\mathrm{Mp}+\mathrm{HCOV}$ & 1 \\
\hline $\mathrm{Mp}+\mathrm{H3}$ & 1 \\
\hline Bacteria & $7(6.36)$ \\
\hline$M p+S$. pneumoniae & 1 \\
\hline$M p+$ S. epidermidis & 1 \\
\hline$M p+$ Alcaligenes spp & 1 \\
\hline$M p+A$. baumannii & 1 \\
\hline$M p+$ Radioactive rhizobia & 1 \\
\hline$M p+$ S. viridans & 1 \\
\hline$M p+S$. saprophyticus & 1 \\
\hline Bacteria and virus & $5(4.55)$ \\
\hline$M p+H R V+S$. pneumoniae & 1 \\
\hline$M p+H M P V+S$. marcescens & 1 \\
\hline$M p+A D V+S$. hominis & 1 \\
\hline$M p+H B o V+K$. oxytoca & 1 \\
\hline$M p+H M P V+H R V+A$. baumannii & 1 \\
\hline
\end{tabular}

Mp Mycoplasma pneumoniae, HRV Rhinovirus, RSV Respiratory syncytial virus, ADV Adenovirus, HPIV Human parainfluenza virus, HMPV Human metapneumovirus, H3 Influenza H3N2, HCoV Human coronavirus, HBoV Human bocavirus, S. pneumoniae Streptococcus pneumoniae, S. epidermidis Staphylococcus epidermidis, S. marcescens Serratia marcescens, A. baumannii Acinetobacter baumannii, S. viridans Streptococcus viridans, S. saprophyticus Staphylococcus saprophyticus, S. hominis Staphylococcus hominis, K. oxytoca Klebsiella oxytoca
(Table 3). The peak incidence of $M p$ detection was in autumn (October to November), while the peak incidence of $M p$ co-detection was in winter. Besides, $M p$ virus co-detection and $M p-H R V$ co-detection occurred throughout the year, with no obvious seasonality. For $M p$-bacteria co-detection, the highest incidence rates were observed in winter and spring (Fig. 1).

\section{Clinical data, laboratory and radiographic findings}

The differences in clinical data, laboratory and radiographic findings among various etiological groups are summarized in Table 4. Fever, cough, and sore throat were the three most common symptoms of children with $M p$ positive. In comparison with mono-detected patients, the duration of fever was significantly longer in $M p$-virus co-detected $(P=0.039)$ and $M p$-virus (excluding HRV $)$ co-detected $(P=0.031)$ patients. Lack of appetite was more prevalent among children with $M p$-virus co-detection $(P=0.022)$. Runny nose was more common in patients with $M p$-virus co-detection $(P=0.012)$ and $M p-H R V$ co-detection $(P=0.002)$. However, the clinical features of patients with $M p$-bacteria co-detection were relatively similar to those with $M p$ mono-detection. No significant differences were noted in terms of the laboratory and radiographic findings among various etiological groups.

\section{Complications, underlying conditions and disease severity parameters}

The differences in complications, underlying conditions and disease severity parameters among various etiological groups are presented in Table 5 . All children with $M p$ positive, including $M p$ mono-detection and $M p$ codetection, did not require PICU admission or invasive mechanical ventilation. However, the cases with severe CAP might require noninvasive mechanical ventilation, and the duration of hospitalization was not significantly different between the patients with $M p$ co-detection and $M p$ mono-detection. However, compared to those with $M p$ mono-detection, $M p$-bacteria co-detected children 
Table 3 The demographic characteristics among various etiological groups

\begin{tabular}{|c|c|c|c|c|c|c|c|c|c|}
\hline Characteristics & $M p(n=68)$ & $M p$-Vir $(n=30)$ & $P$ & $M p-H R V(n=20)$ & $P$ & Mp-Vir (excluding HRV $(n=10)$ & $P$ & $\operatorname{Mp}-\operatorname{Bac}(n=7)$ & $P$ \\
\hline Age, median (IQR) (y) & $6(3)$ & $4(3)$ & 0.009 & $4(3)$ & 0.004 & $5(3.5)$ & 0.045 & $5(5)$ & 0.514 \\
\hline$\leq 1$ year & $0(0)$ & $1(3.33)$ & 0.02 & $0(0)$ & 0.011 & $1(10)$ & 0.205 & $0(0)$ & 0.52 \\
\hline 1 to $\leq 3$ years & $10(14.71)$ & $10(33.33)$ & & $9(45)$ & & $1(10)$ & & $2(28.57)$ & \\
\hline 3 to $\leq 6$ years & $30(44.12)$ & $13(43.33)$ & & $8(40)$ & & $5(50)$ & & $3(42.86)$ & \\
\hline$>6$ years & $28(41.18)$ & $6(20)$ & & $3(15)$ & & $3(30)$ & & $2(28.57)$ & \\
\hline Sex, male & $37(54.41)$ & $19(63.33)$ & 0.411 & $13(65)$ & 0.401 & $6(60)$ & 1 & $4(57.14)$ & 1 \\
\hline \multicolumn{10}{|l|}{ Seasons } \\
\hline Summer(6-8) & $18(26.47)$ & $6(20)$ & 0.929 & $5(25)$ & 0.966 & $1(10)$ & 0.705 & $2(28.57)$ & 0.107 \\
\hline Autumn(9-11) & $24(35.29)$ & $11(36.67)$ & & $6(30)$ & & $5(50)$ & & $0(0)$ & \\
\hline Winter(12-2) & $17(25)$ & $9(30)$ & & $6(30)$ & & $3(30)$ & & $4(57.14)$ & \\
\hline Spring(3-5) & $9(13.24)$ & $4(13.33)$ & & $3(15)$ & & $1(10)$ & & $1(14.29)$ & \\
\hline
\end{tabular}

Data are presented as No. (\%) unless otherwise indicated

Mp Mycoplasma pneumoniae, Mp-Vir Mp-virus co-detection, Mp-HRV Mp-HRV co-detection, Mp-Bac Mp-bacteria co-detection, IQR interquartile range

were more likely to have abnormal blood gases $(P=$ $0.041)$. In addition, the underlying medical conditions of $M p$ co-detected patients were relatively similar to those of $M p$ mono-detected patients.

\section{Discussion}

$M p$ has been recognized as a significant and common cause of pediatric CAP. In this study, it was found that $2.65 \%$ of hospitalized children with CAP experienced $M p$ positive, which is less than $19.1 \%$ reported in Wuhan, China [15]. Such low incidence may be attributed to the different study populations and methods used for $M p$ testing. Previous studies [16-18] have indicated that
$M p$ is detected year-round, and its seasonal peaks have been reported in various seasonal periods starting from the end of summer to winter. In this study, $M p$ positive was more common in autumn, which is consistent with the findings of Chiu et al. [19].

At present, it is widely considered that mixed detections with multiple pathogens are common in children with CAP. Furthermore, $M p$ infection is often associated with preceding or concomitant viral and bacterial infections in children $[19,20]$. In the present study, we found that children with co-detection accounted for $38.18 \%$ of total cases with $M p$ positive. This proportion is lower than that in Taiwan

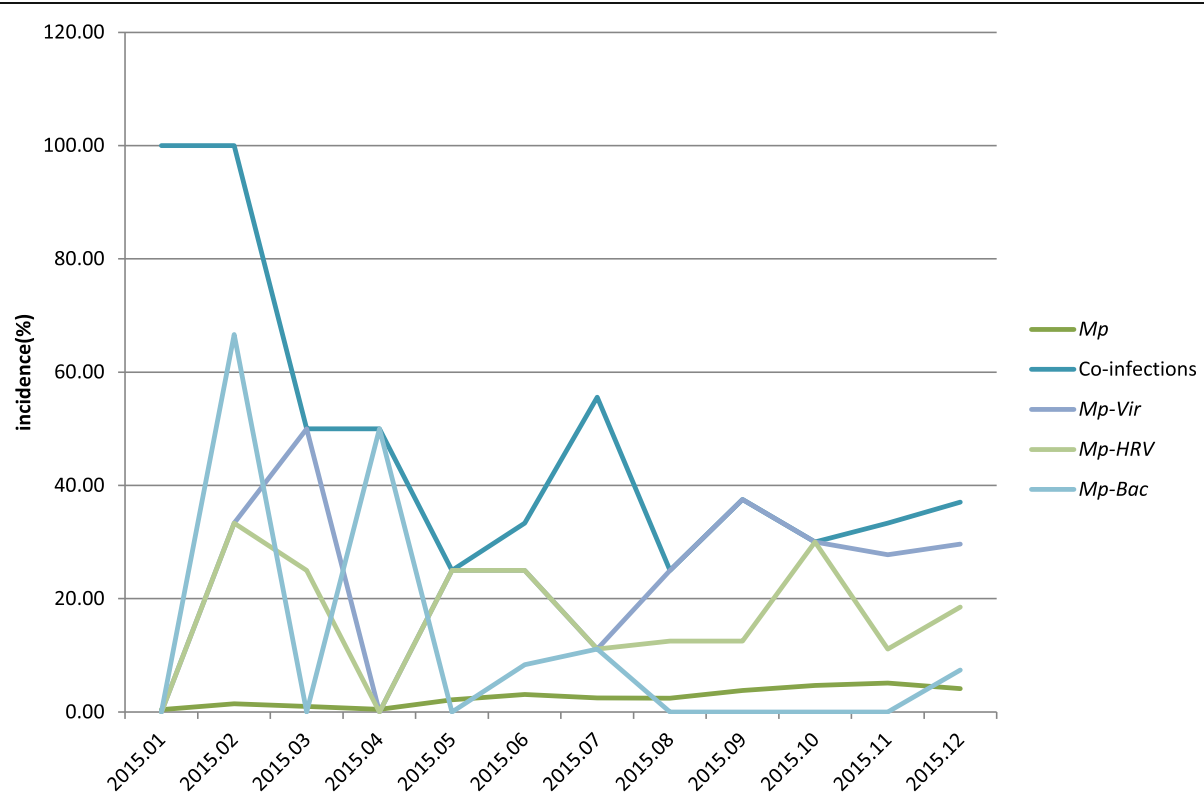

Fig. 1 Seasonal distribution of Mp and Mp co-detection. Mp: Mycoplasma pneumoniae, Mp-Vir: Mp-virus co-detection, Mp-HRV: Mp-HRV codetection, Mp-Bac: Mp-bacteria co-detection 
Table 4 Clinical data, laboratory and radiographic findings among various etiological groups

\begin{tabular}{|c|c|c|c|c|c|c|c|c|c|}
\hline Characteristics & $\begin{array}{l}M p(n= \\
68)\end{array}$ & $\begin{array}{l}\text { Mp-Vir }(n= \\
30)\end{array}$ & $P$ & $\begin{array}{l}M p-H R V(n= \\
20)\end{array}$ & $P$ & $\begin{array}{l}\text { Mp-Vir (excluding HRV } \\
(n=10)\end{array}$ & $P$ & $\begin{array}{l}M p-B a c(n= \\
7)\end{array}$ & $P$ \\
\hline \multicolumn{10}{|l|}{ Clinical data } \\
\hline Fever & $68(100)$ & $29(96.67)$ & 0.306 & $20(100)$ & - & $9(90)$ & 0.128 & $7(100)$ & - \\
\hline Days of total, median(IQR) (d) & $12(7)$ & $14(6)$ & 0.039 & $13.5(8.75)$ & 0.212 & $16(4.5)$ & 0.031 & $11(7)$ & 0.935 \\
\hline Cough & $68(100)$ & $28(93.33)$ & 0.092 & $18(90)$ & 0.05 & $10(100)$ & - & $7(100)$ & - \\
\hline Fatigue & $6(8.82)$ & $6(20)$ & 0.222 & $4(20)$ & 0.325 & $2(20)$ & 0.596 & $1(14.29)$ & 0.512 \\
\hline Lack of appetite & $16(23.53)$ & $14(46.67)$ & 0.022 & $9(45)$ & 0.061 & $5(50)$ & 0.168 & $2(28.57)$ & 1 \\
\hline Dyspnea & $7(10.29)$ & $4(13.33)$ & 0.927 & $2(10)$ & 1 & $2(20)$ & 0.714 & $1(14.29)$ & 0.562 \\
\hline Chills & $4(5.88)$ & $3(10)$ & 0.761 & $2(10)$ & 0.891 & $1(10)$ & 0.506 & $1(14.29)$ & 0.396 \\
\hline Headache & $3(4.41)$ & $1(3.33)$ & 1 & $1(5)$ & 1 & $0(0)$ & 1 & $0(0)$ & 1 \\
\hline Sore throat & 66 (97.06) & $30(100)$ & 1 & $20(100)$ & 1 & $10(100)$ & 1 & $7(100)$ & 1 \\
\hline Wheezing & $1(1.47)$ & $3(10)$ & 0.158 & $2(10)$ & 0.128 & $1(10)$ & 0.241 & $0(0)$ & 1 \\
\hline Runny nose & $0(0)$ & $4(13.33)$ & 0.012 & $4(20)$ & 0.002 & $0(0)$ & - & $0(0)$ & - \\
\hline Abdominal pain & $3(4.41)$ & $1(3.33)$ & 1 & $1(5)$ & 1 & $0(0)$ & 1 & $1(14.29)$ & 0.33 \\
\hline Diarrhea & $1(1.47)$ & $0(0)$ & 1 & $0(0)$ & 1 & $0(0)$ & 1 & $0(0)$ & 1 \\
\hline Vomit & $3(4.41)$ & $3(10)$ & 0.544 & $2(10)$ & 0.689 & $1(10)$ & 0.429 & $0(0)$ & 1 \\
\hline Chest pain & $5(7.35)$ & $0(0)$ & 0.305 & $0(0)$ & 0.484 & $0(0)$ & 1 & $0(0)$ & 1 \\
\hline Rash & $2(2.94)$ & $1(3.33)$ & 1 & $1(5)$ & 0.543 & $0(0)$ & 1 & $0(0)$ & 1 \\
\hline \multicolumn{10}{|l|}{ Laboratory findings } \\
\hline $\begin{array}{l}\text { Leukocyte count, median }(\mathrm{IQR}) \times \\
10^{9} / \mathrm{L}\end{array}$ & $\begin{array}{l}10.35 \\
(5.85)\end{array}$ & $10.4(5.8)$ & 0.691 & $10.4(4.55)$ & 0.812 & $11(12.2)$ & 0.639 & $12.4(7.1)$ & 0.303 \\
\hline Neutrophils, median(IQR) (\%) & $\begin{array}{l}64.55 \\
(13.58)\end{array}$ & $59.9(18.6)$ & 0.137 & $60.6(18.25)$ & 0.142 & $58.55(27.33)$ & 0.509 & $60(16.5)$ & 0.549 \\
\hline Lymphocytes, median (IQR) (\%) & $\begin{array}{l}25.45 \\
(12.03)\end{array}$ & $27.5(15.1)$ & 0.244 & $27.5(19.45)$ & 0.133 & $23.45(19.23)$ & 0.872 & $27.3(17.1)$ & 0.888 \\
\hline $\begin{array}{l}\text { C-reactive protein, } \\
\text { median(IQR)(mg/L) }\end{array}$ & $\begin{array}{l}20.6 \\
(36.55)\end{array}$ & $9.7(34.45)$ & 0.063 & $9.3(34.3)$ & 0.06 & $16.85(58.15)$ & 0.459 & $8.7(23)$ & 0.441 \\
\hline \multicolumn{10}{|l|}{ Radiographic findings } \\
\hline Single lobar infiltrate & $27(39.71)$ & $12(40)$ & 0.978 & $10(50)$ & 0.412 & $2(20)$ & 0.393 & $4(57.14)$ & 0.625 \\
\hline Multilobar infiltrates (unilateral) & $19(27.94)$ & $6(20)$ & 0.406 & $3(15)$ & 0.24 & $3(30)$ & 1 & $0(0)$ & 0.245 \\
\hline Multilobar infiltrates (bilateral) & $19(27.94)$ & $12(40)$ & 0.237 & $7(35)$ & 0.543 & $5(50)$ & 0.296 & $3(42.86)$ & 0.697 \\
\hline Bronchitis & $3(4.41)$ & $0(0)$ & 0.551 & $0(0)$ & 1 & $0(0)$ & 1 & $0(0)$ & 1 \\
\hline Hilar lymphadenopathy & $2(2.94)$ & $3(10)$ & 0.334 & $3(15)$ & 0.134 & $0(0)$ & 1 & $0(0)$ & 1 \\
\hline
\end{tabular}

Data are presented as No. (\%) unless otherwise indicated

Mp Mycoplasma pneumoniae, Mp-Vir Mp-virus co-detection, Mp-HRV Mp-HRV co-detection, Mp-Bac Mp-bacteria co-detection, IQR interquartile range

population [19] and higher than that in Beijing population [20]. However, the incidence of mixed detections with viruses was $27.27 \%$ in this study, which is higher compared to both Taiwan and Beijing populations. These differences may be due to the exclusion of $H R V$ test in their studies. HRV is the most prevalent respiratory virus and is often associated with the common cold. Moreover, $H R V$ may be associated with more severe lower respiratory tract infections in children, including bronchiolitis and pneumonia [21]. The results of this study showed that $H R V$ was the most common pathogen among children with $M p$ codetection, at a frequency of up to $18.18 \%$. Thus, researchers and pediatricians should pay more attention to $M p-H R V$ co-detection among children with CAP. Age is an important factor that can affect pathogen distribution. The incidence of $M p$ infection is highest among children aged 3-7 years, while respiratory viral infections are more common in children younger than 2 years $[22,23]$. Likewise, in this study, the patients with $M p$-virus co-detections were significantly younger, especially prevalent among those $\leq 3$ years old.

$M p$-infected children can present with fever, cough, chest pain and wheeze, along with non-respiratory symptoms such as arthralgia and headache [24]. In the present 
Table 5 Complications, underlying conditions and disease severity parameters among various etiological groups

\begin{tabular}{|c|c|c|c|c|c|c|c|c|c|}
\hline Characteristic & $\begin{array}{l}M P(n= \\
68)\end{array}$ & $\begin{array}{l}\text { Mp-Vir } \\
(n=30)\end{array}$ & $P$ & $\begin{array}{l}\text { Mp-HRV } \\
(n=20)\end{array}$ & $P$ & $\begin{array}{l}\text { Mp-Vir (excluding HRV) } \\
(n=10)\end{array}$ & $P$ & $\begin{array}{l}\text { Mp-Bac } \\
(n=7)\end{array}$ & $P$ \\
\hline \multicolumn{10}{|l|}{ Complications $^{a}$} \\
\hline Any condition ( $\geq 1$ condition) & $\begin{array}{l}55 \\
(80.88)\end{array}$ & $29(96.67)$ & 0.081 & $20(100)$ & 0.078 & $9(90)$ & 0.795 & $7(100)$ & 0.454 \\
\hline Pleural effusion & $\begin{array}{l}35 \\
(51.47)\end{array}$ & $13(43.33)$ & 0.458 & $6(30)$ & 0.091 & $7(70)$ & 0.449 & $5(71.43)$ & 0.542 \\
\hline Small & $1(1.47)$ & $1(3.33)$ & 0.144 & $1(5)$ & 0.092 & $0(0)$ & 0.433 & $2(28.57)$ & 0.073 \\
\hline Moderate & $\begin{array}{l}33 \\
(48.53)\end{array}$ & $10(33.33)$ & & $4(20)$ & & $6(60)$ & & $3(42.86)$ & \\
\hline Massive & $1(1.47)$ & $2(6.67)$ & & $1(5)$ & & $1(10)$ & & $0(0)$ & \\
\hline Consolidation & $\begin{array}{l}37 \\
(54.41)\end{array}$ & $20(66.67)$ & 0.257 & $13(65)$ & 0.401 & $7(70)$ & 0.557 & $7(100)$ & 0.054 \\
\hline Lobar or unilateral change & $34(50)$ & $17(56.67)$ & 0.721 & $11(55)$ & 0.83 & $6(60)$ & 0.513 & $6(85.71)$ & 0.513 \\
\hline Bilateral pulmonary multiple change & $3(4.41)$ & $3(10)$ & & $2(10)$ & & $1(10)$ & & $1(14.29)$ & \\
\hline Pulmonary atelectasis & $7(10.29)$ & $5(16.67)$ & 0.581 & $5(25)$ & 0.189 & $0(0)$ & 0.586 & $2(28.57)$ & 0.196 \\
\hline Liver dysfunction & $8(11.76)$ & $4(13.33)$ & 1 & $3(15)$ & 1 & $1(10)$ & 1 & $0(0)$ & 1 \\
\hline Myocardial damage & $\begin{array}{l}18 \\
(26.47)\end{array}$ & $7(23.33)$ & 0.743 & $5(25)$ & 0.895 & $2(20)$ & 0.96 & $1(14.29)$ & 0.803 \\
\hline $\begin{array}{l}\text { Abnormal blood gas (hypoxemia, } \\
\text { hypokalemia, etc.) }\end{array}$ & $2(2.94)$ & $1(3.33)$ & 1 & $0(0)$ & 1 & $1(10)$ & 0.341 & $2(28.57)$ & 0.041 \\
\hline Central nervous system infection & $1(1.47)$ & $1(3.33)$ & 0.521 & $0(0)$ & 1 & $1(10)$ & 0.241 & $0(0)$ & 1 \\
\hline \multicolumn{10}{|l|}{ Underlying conditions } \\
\hline Any condition ( $\geq 1$ condition) & $8(11.76)$ & $4(13.33)$ & 1 & $3(15)$ & 1 & $1(10)$ & 1 & $1(14.29)$ & 1 \\
\hline $\begin{array}{l}\text { Respiratory disease (asthma, congenital } \\
\text { malformation etc.) }\end{array}$ & $2(2.94)$ & $2(6.67)$ & 0.76 & $1(5)$ & 0.543 & $1(10)$ & 0.341 & $0(0)$ & 1 \\
\hline Neurological Disease (epilepsy) & $2(2.94)$ & $0(0)$ & 1 & $0(0)$ & 1 & $0(0)$ & 1 & $0(0)$ & 1 \\
\hline Congenital heart disease & $0(0)$ & $2(6.67)$ & 0.092 & $2(10)$ & 0.05 & $0(0)$ & - & $0(0)$ & - \\
\hline \multicolumn{10}{|l|}{ Disease severity parameters } \\
\hline Severe $C A P^{b}$ & $\begin{array}{l}49 \\
(72.06)\end{array}$ & $19(63.33)$ & 0.388 & $10(50)$ & 0.065 & $9(90)$ & 0.409 & $6(85.71)$ & 0.742 \\
\hline PICU admission & $0(0)$ & $0(0)$ & - & $0(0)$ & - & $0(0)$ & - & $0(0)$ & - \\
\hline Noninvasive positive pressure ventilation & $4(5.88)$ & $2(6.67)$ & 1 & $1(5)$ & 1 & $1(10)$ & 0.506 & $0(0)$ & 1 \\
\hline Invasive mechanical ventilation & $0(0)$ & $0(0)$ & - & $0(0)$ & - & $0(0)$ & - & $0(0)$ & - \\
\hline Length of stay, median(IQR) (d) & $13(5)$ & $14(6)$ & 0.177 & $14.5(6)$ & 0.163 & $13.5(7)$ & 0.599 & $11(3)$ & 0.319 \\
\hline
\end{tabular}

Data are presented as No. (\%) unless otherwise indicated

Mp Mycoplasma pneumoniae, Mp-Vir Mp-virus co-detection, Mp-HRV Mp-HRV co-detection, Mp-Bac Mp-bacteria co-detection, IQR interquartile range

${ }^{a}$ All cases of pulmonary atelectasis are single lobar; All cases of liver dysfunction, myocardial damage and abnormal blood gas are mild;

${ }^{b}$ The diagnosis criteria of severe CAP are in accordance with the Chinese Medical Association Guidelines for the management of community-acquired pneumonia in children (revised 2013) (Chin J Pediatr. 2013; 51(11):856-62)

study, we found that, similar to $M p$ mono-detection, fever, cough and sore throat were the three main symptoms of $M p$ co-detection, followed by nonrespiratory symptoms, including rash, headache and abdominal pain. In addition, there were some differences in the clinical symptoms between patients with co-detection and mono-detection. First, compared to $M p$ mono-detection children, the duration of fever was significantly longer in children with $M p$-virus and $M p$-virus (excluding $H R V$ ) co-detection. Second, lack of appetite was more prevalent in children with
$M p$-virus co-detection. Third, runny nose was more common in patients with $M p$-virus co-detection and $M p-H R V$ co-detection. However, the clinical symptoms are relatively non-specific, indicating that these parameters may not be helpful to distinguish $\mathrm{Mp}$ codetection from $M p$ mono-detection.

A recent study shows that the clinical outcomes of $M p$ infection are heavily dependent on the co-infected pathogen [20]. Pientong et al. [25] have reported that $M p$ may serve as an important co-infectious agent of respiratory viruses, which increases the severity of acute 
childhood bronchiolitis. However, no significant differences were noted in the incidence of severe CAP, duration of hospitalization, and noninvasive mechanical ventilation among various etiological groups in the present study, suggesting that mixed detection of $M p$ with other viral or bacterial pathogen does not contribute to the severity of CAP. Chiu et al. [19] demonstrate that no significant difference is observed between the patients infected with $M p$ and those co-infected with virus, as similar to that reported in our study. To avoid overestimation of $M p-H R V$ co-detection, we further investigated the differences in clinical outcomes between children with $M p$-virus (excluding $H R V$ ) co-detection and $M p$ mono-detection. Similarly, there was no significant difference between the two groups. Then, we further explored the role of $M p-H R V$ co-detection in children with CAP. Notably, a similar distribution of most complications, underlying conditions and disease severity parameters were found between the two groups. These results indicate that $M p-H R V$ co-detection may have little influence on the clinical outcomes of CAP. Likewise, we found no significant difference in the clinical outcomes between $M p$-bacteria co-detection and $M p$ mono-detection, except that $M p$-bacteria codetection was more likely to be associated with abnormal blood gases. However, our results might differ from with the findings $[19,20]$ of different regions of China, suggesting that $S$. pneumoniae co-infection can lead to greater disease severity in children with $M p$ infection compared to single infection.

With the use of molecular diagnostics, co-detection with other viral/bacterial pathogens has been commonly identified in $M p$ positive patients. Nonetheless, this study confirms that the clinical features and severity of $M p$ mono-detected patients are relatively similar to those co-detected with viral and/or bacterial pathogens. Thus, we speculate that a large proportion of CAP patients may be infected with a major pathogen of pneumonia (i.e. $M p$ ) and tend to have a colonization of other pathogens in respiratory tract [26]. Furthermore, it is also possible that the viral or bacterial pneumonia patients may have a serologic evidence of past $M P$ infection (IgM positive) or PCR positive (colonization).

Nevertheless, this study has several limitations. The presence of co-infection should be confirmed by serologic tests at least 2 times during hospitalization or convalescent stage. However, it is very difficult to apply at clinical fields, owing to lack of available methods. In this study, due to the limits of current respiratory bacteria detection methods, the pattern of identified pathogens might not accurately represent the CAP, especially in young children. Moreover, the small sample size could impose restrictions on determining the association between $M p$ co-detection and disease severity. In addition, this single center study might not be representative of the entire Chinese pediatric population.

\section{Conclusions}

In conclusion, we concluded that though $M p$ co-detection with viral and/or bacterial pathogens is common in clinical practice, there are no apparent differences between $M p$ mono-detection and $M p$ co-detections in terms of clinical features and disease severity. Our findings may eventually contribute to a better understanding of the implication of $M p$ co-detections in clinical practice, which is essential to improve preventive and therapeutic strategies.

\section{Abbreviations}

09H1: Influenza A H1N1 pdm09; ADV: Adenovirus; BALF: Bronchoalveolar lavage fluid; CAP: Community-acquired pneumonia; Ch: Chlamydia; CRP: C-reactive protein; Flu A: Influenza A; Flu B: Influenza B; H3: Influenza H3N2; HBoV: Human bocavirus; HCoV: Human coronavirus; HMPV: Human metapneumovirus; HPIV: Human parainfluenza virus; HRV: Rhinovirus; Mp: Mycoplasma pneumoniae; NPAs: Nasopharyngeal aspirates; PCR: Polymerase chain reaction; RSV: Respiratory syncytial virus

\section{Acknowledgements}

Not applicable.

\section{Authors' contributions}

$M Z, G L$ and ZF conceived the study. MZ, LW and FQ performed the experiments. LZ, WG and SY conducted the clinical work. MZ wrote this article, ZF revised it. All the authors have read and approved the final version of this manuscript.

\section{Funding}

This work was supported by grants from the Hebei Key Project Plan for Medical Science Research $(20190834,20180616,20170402)$. The funding body had no role in the design of the study and collection, analysis, and interpretation of data and in writing the manuscript.

\section{Availability of data and materials}

The datasets used and/or analyzed during the current study available from the corresponding author on reasonable request.

\section{Ethics approval and consent to participate}

This study was approved by the Institutional Review Board of Children's Hospital of Hebei Province, affiliated to Hebei Medical University. The written informed consent was obtained from each patient's parent prior to enrollment.

\section{Consent for publication}

Not applicable.

\section{Competing interests}

The authors declare that they have no competing interests.

\section{Author details}

${ }^{1}$ Institute of Pediatric Research, Children's Hospital of Hebei Province, affiliated to Hebei Medical University, 133 Jianhua South Street, Shijiazhuang 050031, Hebei Province, China. ${ }^{2}$ Graduate School of Hebei Medical University, 361 Zhongshan East Road, Shijiazhuang 050017, Hebei Province, China.

${ }^{3}$ Department of Laboratory Medicine, People's Hospital of Hebei Province, 384 Heping West Road, Shijiazhuang 050051, Hebei Province, China.

Received: 18 April 2019 Accepted: 29 August 2019

Published online: 11 October 2019

\section{References}

1. Cevey-Macherel M, Galetto-Lacour A, Gervaix A, Siegrist CA, Bille J, BescherNinet B, Kaiser L, Krahenbuhl JD, Gehri M. Etiology of community-acquired 
pneumonia in hospitalized children based on WHO clinical guidelines. Eur J Pediatr. 2009;168:1429-36.

2. Don $M$, Fasoli L, Paldanius $M$, Vainionpää $R$, Kleemola $M$, Räty $R$, Leinonen M, Korppi M, Tenore A, Canciani M. Aetiology of community-acquired pneumonia: serological results of a paediatric survey. Scand J Infect Dis. 2005;37:806-12.

3. Honkinen M, Lahti E, Österback R, Ruuskanen O, Waris M. Viruses and bacteria in sputum samples of children with community-acquired pneumonia. Clin Microbiol Infect. 2012;18:300-7.

4. Jain S, Williams DJ, Arnold SR, Ampofo K, Bramley AM, Reed C, Stockmann C, Anderson EJ, Grijalva CG, Self WH, et al. Community-acquired pneumonia requiring hospitalization among U.S. children [J]. N Engl J Med. 2015;372(9): 835-45.

5. Liu WK, Liu Q, Chen DH, Liang HX, Chen XK, Chen MX, Qiu SY, Yang ZY, Zhou R. Epidemiology of acute respiratory infections in children in Guangzhou: a three-year study [J]. PLoS One. 2014;9(5):e96674.

6. Ferwerda A, Moll HA, de Groot R. Respiratory tract infections by Mycoplasma pneumoniae in children: a review of diagnostic and therapeutic measures. Eur J Pediatr. 2001;160:483-91.

7. Juven T, Mertsola J, Waris M, Leinonen M, Meurman O, Roivainen M, Eskola J, Saikku P, Ruuskanen O. Etiology of community-acquired pneumonia in 254 hospitalized children. Pediatr Infect Dis J. 2000;19:293-8.

8. Michelow IC, Olsen K, Lozano J, Rollins NK, Duffy LB, Ziegler T, Kauppila J, Leinonen M, McCracken GH. Epidemiology and clinical characteristics of community-acquired pneumonia in hospitalized children. J Pediatr. 2004; 113:701-7.

9. Chen CJ, Lin PY, Tsai MH, Huang CG, Tsao KC, Wong KS, Chang LY, Chiu CH, Lin TY, Huang YC. Etiology of community-acquired pneumonia in hospitalized children in northern Taiwan. Pediatr Infect Dis J. 2012;31:e196201.

10. Heiskanen-Kosma T, Korppi M, Jokinen C, Kurki S, Heiskanen L, Juvonen H, Kallinen S, Stén M, Tarkiainen A, Rönnberg PR, et al. Etiology of childhood pneumonia: serologic results of a prospective, population-based study. Pediatr Infect Dis J. 1998;17:986-91.

11. The Subspecialty Group of Respirology, the Society of Pediatrics, Chinese Medical Association. The editorial board of Chinese journal of pediatri. Guidelines for the management of community-acquired pneumonia in children (revised 2013). Chin J Pediatr. 2013;51(11):856-62.

12. Xu D, Li S, Chen Z, Du L. Detection of Mycoplasma pneumoniae in different respiratory specimens. Eur J Pediatr. 2011;170(7):851-8.

13. Bradley JS, Byington CL, Shah SS, Alverson B, Carter ER, Harrison C, Kaplan SL, Mace SE, McCracken GH Jr, Moore MR, et al. The management of community-acquired pneumonia in infants and children older than 3 months of age: clinical practice guidelines by the Pediatric Infectious Diseases Society and the Infectious Diseases Society of America. Clin Infect Dis. 2011;53(7):e25-76.

14. Zhao M-C, Li G-X, Zhang D, Zhou H-y, Wang H, Yang S, Wang L, Feng Z-S, Ma X-j. Clinical evaluation of a new single-tube multiplex reverse transcription PCR assay for simultaneous detection of 11 respiratory viruses, Mycoplasma pneumoniae and Chlamydia in hospitalized children with acute respiratory infections. Diagn Microbiol Infect Dis. 2017;88:115-9.

15. Liu J, Ai H, Xiong Y, Li F, Wen Z, Liu W, Li T, Qin K, Wu J, Liu Y. Prevalence and correlation of infectious agents in hospitalized children with acute respiratory tract infections in Central China. PLoS One. 2015;10(3):e01 19170. https://doi.org/10.1371/journal.pone.0119170.

16. Luby JP. Pneumonia caused by Mycoplasma pneumoniae infection. Clin Chest Med. 1991;12:237-44

17. Johnson DH, Cunha BA. Atypical pneumonias. Clinical and extrapulmonary features of Chlamydia, Mycoplasma, and Legionella infections. Postgrad Med. 1993;93:69-72, 75-76, 79-82.

18. Lieberman D, Porath A. Seasonal variation in community acquired pneumonia. Eur Respir J. 1996;9:2630-4.

19. Chiu C-Y, Chen C-J, Wong K-S, Tsai M-H, Chiu C-H, Huang Y-C. Impact of bacterial and viral coinfection on mycoplasmal pneumonia in childhood community-acquired pneumonia. J Microbiol Immunol Infect. 2015;48:51-6.

20. Song Q, Xu B-P, Shen K-L. Effects of bacterial and viral co-infections of mycoplasma pneumoniae pneumonia in children: analysis report from Beijing Children's hospital between 2010 and 2014. Int J Clin Exp Med. 2015; 8(9):15666-74.

21. Louie JK, Roy-Burman A, Guardia-Labar L, Boston EJ, Kiang D, Padilla T, Yagi S, Messenger S, Petru AM, Glaser CA, et al. Rhinovirus associated with severe lower respiratory tract infections in children. Pediatr Infect Dis J. 2009;28(4): 337-9. https://doi.org/10.1097/INF.0b013e31818ffc1b.

22. Youn YS, Lee KY, Hwang JY, Rhim JW, Kang JH, Lee JS, Kim JC. Difference of clinical features in childhood Mycoplasma pneumoniae pneumonia. BMC Pediatr. 2010;10:48.

23. Liu XT, Wang GL, Luo XF, Chen YL, Ou JB, Huang J, Rong JY. Spectrum of pathgens for community-acquired pneumonia in children. Zhongguo Dang Dai Er Ke Za Zhi. 2013;15:42-5.

24. Harris M, Clark J, Coote N, Fletcher P, Harnden A, McKean M, Thomson A, British Thoracic Society Standards of Care Committee. British thoracic society guidelines for the management of community acquired pneumonia in children: update 2011. Thorax. 2011;66(Suppl 2):ii1-23.

25. Pientong C, Ekalaksananan T, Teeratakulpisarn J, Tanuwattanachai S, Kongyingyoes B, Limwattananon C. Atypical bacterial pathogen infection in children with acute bronchiolitis in Northeast Thailand. J Microbiol Immunol Infect. 2011;44:95-100.

26. Youn YS, Lee KY. Mycoplasma pneumoniae pneumonia in children. Korean J Pediatr. 2012;55(2):42-7.

\section{Publisher's Note}

Springer Nature remains neutral with regard to jurisdictional claims in published maps and institutional affiliations.
Ready to submit your research? Choose BMC and benefit from:

- fast, convenient online submission

- thorough peer review by experienced researchers in your field

- rapid publication on acceptance

- support for research data, including large and complex data types

- gold Open Access which fosters wider collaboration and increased citations

- maximum visibility for your research: over $100 \mathrm{M}$ website views per year

At BMC, research is always in progress.

Learn more biomedcentral.com/submissions 